\title{
HIV/AIDS Awareness Level in Secondary Schools of India after Twenty Seven Years
}

\author{
Dr. Shikha Trivedi \\ Department of Early Childhood, BA ISAGO University College, Botswana
}

\begin{abstract}
The Acquired Immuno Deficiency Syndrome (AIDS) epidemic is in its third decade and has become a pandemic disease that threatens the world population. It affects the whole body systems as well as the mental health and social relationships of carriers and asymptomatic patients. Young people are, both, an important group and potential resource for the prevention of HIV/AIDS, as it is the younger generation that is most infected and affected. Many young people lack basic information about HIV and AIDS till today after twenty five years of prevalence, and are unaware of the ways in which HIV infection can be prevented. Thus, the study was undertaken. The School and Education system in all over the world play a major role in shaping the attitudes, opinions and the behavior of young people. This implies that school curriculum should be such that increases the awareness of HIV/AIDS that equip the students with proper skills to combat this pandemic. Questionnaire was used to collect quantitative data. Data was analyzed using SPSS VERSION 17.0 and findings of the study revealed that students were still lacking in basic knowledge regarding HIV/AIDS. There is a need to provide additional resources and conduct workshops to the students. Parents' involvement on HIV/AIDS issues can really backup the understanding of HIV/AIDS among children.
\end{abstract}

Key words: HIV/AIDS, school and education system, combat, awareness and knowledge

\subsection{Introduction}

\section{Introduction}

HIV/AIDS was first recognized as a new disease about twenty-three years ago. Since then disease became a 'pandemic' and illness that is spreading quickly across the world. India is one of the largest and most populated countries in the world. It is estimated that around 2.5 million people out of over one billion people are currently living with HIV [1]. In Asia and the Pacific, nearly 351,000 people became newly infected in 2012, bringing the total number of people living with HIV/AIDS there to nearly 5 million. AIDS claimed an estimated 261,000 lives in the region in 2012 [2]..

When an individual acknowledges risk, but feels powerless to do anything about it, then the person may cope by denial of the risk. Therefore, people do not need to know what to do, they need to know "how" to do and to have the opportunity to practice and feel they are capable of changing. Many young people lack basic information about HIV and AIDS, and are unaware of the ways in which HIV infection can occur, and of the ways in which HIV Infection can be prevented. Schools are an excellent point of contact for young peoplealmost all people attend school for some part of their childhood, and while they are there, they expect to learn new information, and are more receptive to it than they might be in another environment [3] .

At the beginning of 1986, India had no reported cases of HIV/AIDS.. The first case of HIV was diagnosed among sex workers in Chennai, Tamil Nadu and it was noted that contact with foreign visitors had played a role in initial infections [4]. Since then HIV has spread extensively throughout the country. In 1990 there had been tens of thousands of people living with HIV in India; by 2000 this had risen to millions [5].

Affected children are often traumatised and suffer a variety of psychological reaction to parental illness and death. In addition, they feel insecurity and stigmatization as it is assumed that that they too are infected with HIV. Existing studies of the children's reactions suggest that they tend to show internalising rather than externalising symptoms such as depression, anxiety, and withdrawal. Stigma continues to be major challenge regardless of how long HIV/AIDS is apparent in the myths surrounding transmission, prevention and cure. Communities need more education on issues of HIV/AIDS, especially to try and decrease the extent to which people are subject to stigma.

Educating people about HIV/AIDS and how it can be prevented is complicated in India, due to number of factors like poverty, lack of information and communication awareness in people, religious mythology, socio-economic status etc. This means that although some HIV/AIDS prevention and information with education had taken place, it is far from facing and creating a combative effort to eradicate or reduce the pandemic. Most young people become sexually active in their teens, and by that time they need to know how to prevent themselves becoming infected with HIV. HIV campaigns often fail to address the increased vulnerability of girls and women to infection. The best method for empowering girls and women to make these 
choices is to ensure that they receive an education. The education would be a large step towards turning around the HIV/AIDS epidemic [6].

In India, there is a discrepancy between the large amount of effort invested in HIV/AIDS curriculums and training packages on a national level and the lack of actual education being carried out in many schools. Some officials, social and political leaders including the society itself have been reluctant to encourage the effective AIDS Education system that can play a vital part to curb and combat to deal with HIV/AIDS, claiming that the problem is not significant. Both countries spend a huge portion of their budget on education. Presenting the budget in the parliament on Friday, Feb 26, Pranab Mukherjee said, "I propose to increase the plan allocation for school education from Rs 26,800 crore in $2009-10$ to Rs 31,036 crore in 2010-11". This accounts for an increase of Rs 4,236 crore from the 2009-10 fiscal.[7].

\subsection{Justification of the study}

The Researcher has realized that after almost thirty years of existence of HIV/AIDS, students and teachers are still not equipped to fight against this pandemic, although school is considered to be a focal point or a very crucial platform to discuss these issues. The researcher has observed a typical negative attitude of teachers towards HIV/AIDS infected/affected pupils due to many factors that hinders Social and Intellectual development of children. Such attitude and behaviour also hinders the efforts that Society and Government seriously embarking on to fight this pandemic.

\subsection{Objective}

Objective of the study was to find out the extent of HIV/AIDS awareness among Secondary School students in India after twenty seven years of its existence.

\section{Methodology}

Exploratory research approach was used for the present Investigation. The study was carried out using quantitative research method that uses objective measurements and numerical or statistical analysis in trying to explain the causes of the changes. The study was conducted at Gurgaon, Ajmer, Mumbai and Noida. Total of six Secondary Schools from each place were purposively selected so that the respondents can be easily accessible. Then out of six schools, two schools were randomly selected to avoid any kind of biasness in sampling of schools thus, making the total of 8 secondary schools all together. Purposive sampling was used for students' selection. Total sample of ten students ( 5 from class 8 and 5 from class 9 ) were selected from each school. Out of five, one student was an average academic performer, two with low academic performance and two with high academic performance Questionnaire was used to collect data. Questionnaire had two sections: Section A was to get the background information about the sample and Section B had some basic awareness questions to test the extend of awareness level of the samples. Data was analyzed using SPSS 17.0 version and results are explained in the form of charts and tables.

\section{Result Findings}

Findings were analyzed and are presented below:

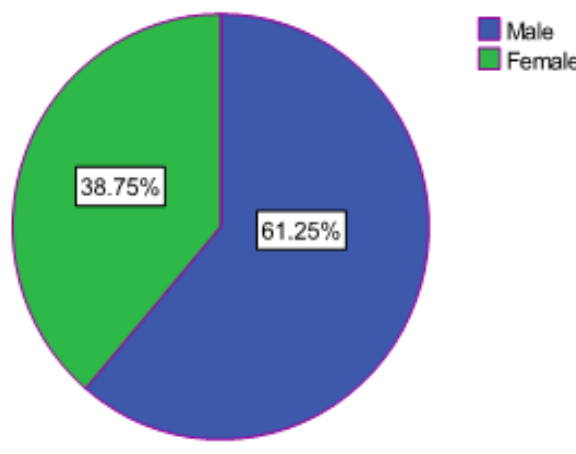

Figure 1: Gender of students

Data from the Fig, 1 shows that there were $61.3 \%$ male and, $38.8 \%$ female . It may be the coincidence due to the criteria use for selection of the samples. 


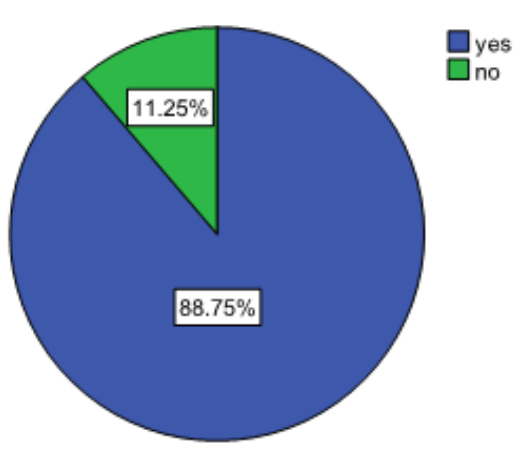

Figure 2: Whether students have heard of about HIV/AIDS?

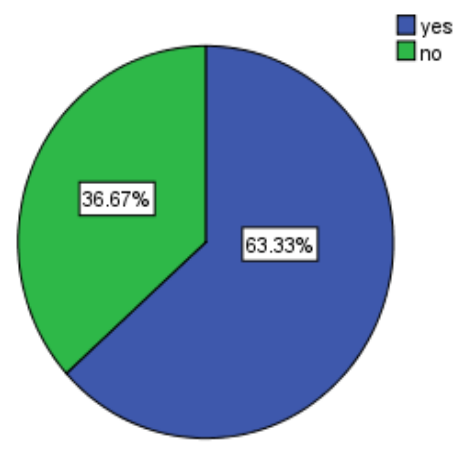

Figure 3: Students view on importance teaching HIV/AIDS topic in class

Fig 2 shows that $88.3 \%$ of students had and $11.3 \%$ had not heard about HIV/AIDS. This gave a clue that after twenty three years of this pandemic and continuous effort by the government to fight against this disease, students were still not informed about this pandemic.Data in Fig.3 reveals $63.3 \%$ students accepted that it is important to teach about HIV/AIDS, whereas, $36.7 \%$ respondents did not see this as an important topic. It is a clear sign of negligence on the part of adolescents who are failing to understand the importance of this topic. Students who accepted the importance of the topic gave reason that it was important to know for personal safety and general awareness. It can be inferred that schools are trying to increase students awareness about the issues that can affect their health and one of them is HIV/AIDS. Some experts like Haimanti Mukerjee, gynaecologist Ranjana Sharma, sexologist Dr. Chadha and Mukta Vasai ,consultant child psychologist have expressed that in India this is high time that sex education should be started in primary and secondary school right from 6th or 7th classes [8]. Findings of the present study is in line with the study conducted by the Department of Educations' life skills program on evaluation of HIV and Aids prevention among Grade 9 students in 22 randomly allocated schools in KwaZulu-Natal, South Africa, that showed only a significant increase in student knowledge about HIV/AIDS in the intervention group compared with the control group [9].

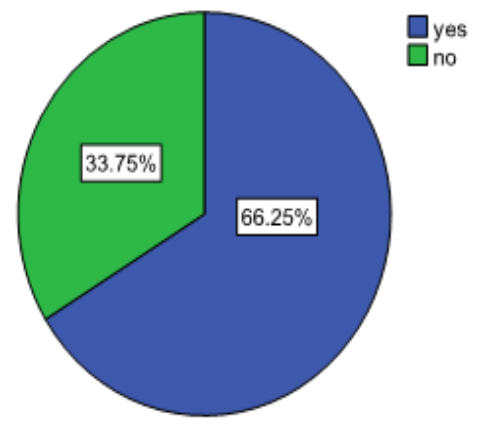

Figure 4: Teaching of HIV topics In the class room

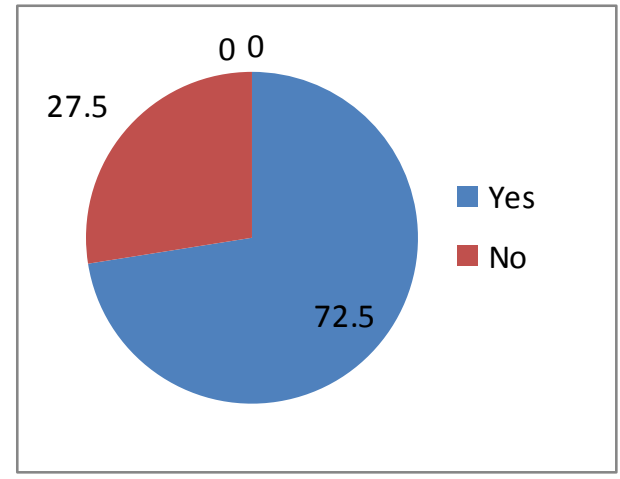

Figure 5 Other places of information in school besides class room

Fig. 4 illustrates $66.3 \%$ of the respondents informed that HIV/AIDS is a part of their curriculum whereas rest denied.. It is important to inform here that although $33.8 \%$ students have indicated that the topic is not taught in the class, it was not possible to single out any place in India where one can say that HIV/AIDS related topic is not discussed. The negative answer may be due to ignorance towards HIV/AIDS since it is still considered as restrictive subject to discuss in some families.

According to the Fig. 5, 72.5\% respondents indicated that there were places in school other than class room where the information on HIV/AIDS was displayed. The places named were: library (52.5\%), school clubs (7.5\%), assembly (11.3\%), guidance \& counseling (32.5\%), and notice board (20\%). It clearly showed that schools were trying to make sure to provide information to the students within the school about HIV/AIDS besides classroom. It can be inferred that India is trying to provide good basic foundation on HIV/AIDS related issues at secondary level. Experts also agree that prevention through education is the best way to fight the transmission of human immune deficiency virus, which causes AIDS and that education must begin before young people initiate sexual activity and certainly no later than seventh grade [10]. It is worth to note that major subject to discuss about this topic is science. The results concurred with other study which has stated that Where AIDS education is carried out in India it is incorporated into science lessons, with students being taught purely about the biological aspects of the subject. This approach has advantages, in that it is more adaptable to teachers 
who have not received any training to teach about AIDS and avoids the cultural and religious barriers that make it difficult for teachers to talk about sex in the classroom [11]. At the same time, most experts agree that programmes that address the social side of HIV and AIDS are more effective than purely scientific approaches, which can make it difficult for students to appreciate the 'human' side of the topic [12].

Table 1: Statements to test awareness level of students

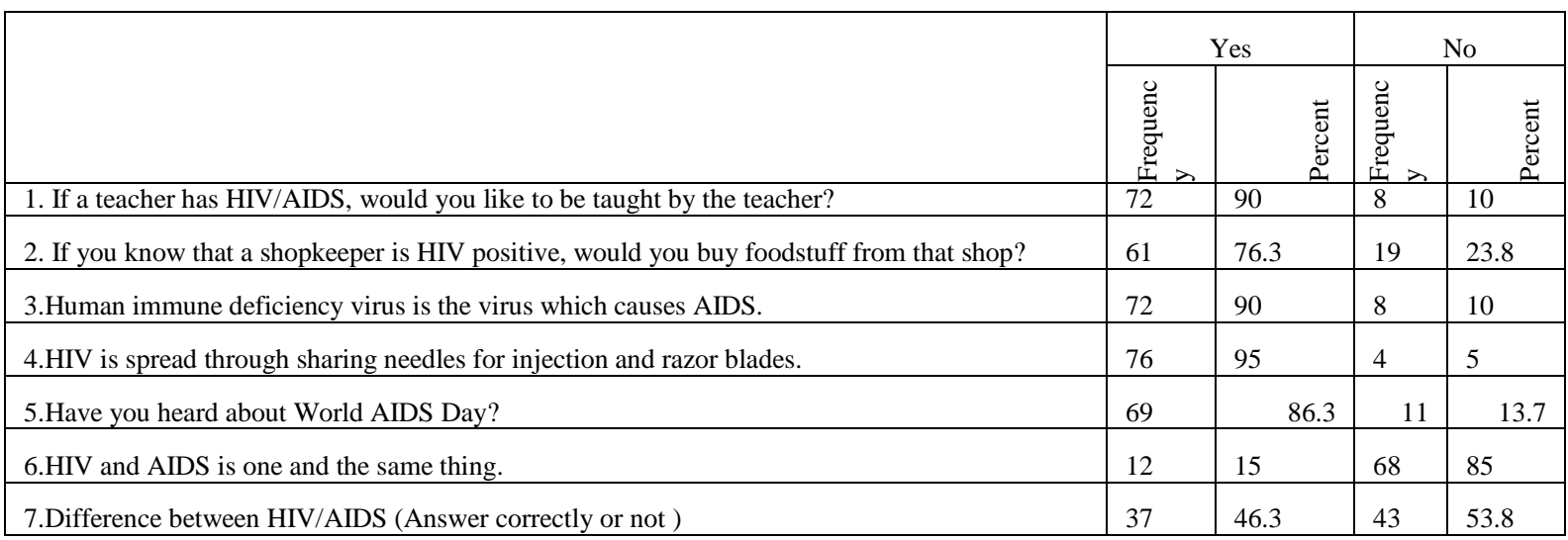

Results in table 1 shows that:

- $\quad 90 \%$ students had no problem of being taught with HIV infected teachers.

- $76.3 \%$ students had no problem in buying food stuff with HIV infected shopkeeper.

- $\quad 90 \%, 95 \%$ students accepted the statements 3 and 4 ,respectively.

- $86.3 \%$ students had heard about World AIDS Day.

- For statement 6 and 7, 85\% students denied that HIV and AIDS is one thing and out of $85 \%, 46.3 \%$ managed to correctly state the difference between the two .

A study conducted in Iran also revealed that $67-96 \%$ students correctly answered the questions. However, many misconceptions were still noted relating to HIV/AIDS, with $9 \%$ of students believing that children would never be affected by HIV/AIDS, $10 \%$ believing that HIV-positive people can be recognized by their appearance, $9 \%$ and $11 \%$ believing that there is a cure and vaccine for AIDS respectively [13]. A study conducted amongst the secondary school students in Haryana and Jamnagar confirmed that although all the students had heard of HIV/AIDS although only $51.4 \%$ were able to write the full form of AIDS and only $19.9 \%$ were able to write the full form of HIV [14]. In another study gaps were seen in the awareness about other modes of transmission, only $31.1 \%$ and $23.4 \%$ cited blood transfusion and mother to baby transmission as routes of transmission, respectively. Low levels of knowledge about general aspects and transmission of HIV/AIDS have also been observed amongst secondary school students [15].

After calculating the mean of awareness level of students, it was found out that $37.5 \%$ respondents' awareness level was above average, $35 \%$ showed average level of awareness, whereas $27.5 \%$ awareness level was below average but there was no difference in between the mean of boys and girls awareness level. It was very good to recognize that schools can help to reduce the vulnerability of girls to HIV and AIDS by empowering them with knowledge. Education can contribute to female economic independence, delayed marriage, and family planning. Several studies have demonstrated the fact that education can protect women from HIV.

\section{Conclusion And Recommendations:}

HIV/AIDS is still a disease of concern. After so many years, education sector is not fully equipped with the resources (human \& non-human) and to some people, it is still a stigma. Basic information on HIV/AIDS is given in schools but need to put more efforts in secondary schools. Library was identified as a place of information besides classroom. Topic does not need to be stand alone but can be taught in conjunction with other subjects. Teachers need to be positive while delivering lecture on HIV related issues.

\subsection{Recommendations:}

1. A same research study can be taken on a larger sample including those from urban, rural and tribal areas to increase the generalization of the results. 
2. A comparative study of same nature can be undertaken on a sample from different districts in India and different regions in Botswana.

3. A research study can be conducted to see the effectiveness of the teaching aids used in imparting knowledge on HIV/AIDS issues at different school levels.

\section{References}

[1]. UNAIDS, 2.5 million People in India living with HIV, 2007, http://www.unaids.org, retrieved on 02/02/11.

[2]. UNAIDS Fact Sheet 2013, UNAIDS report on the global AIDS epidemic, http://www.unaids.org, retrieved on 28/ 12/13

[3]. UNAIDS and WHO (2004). Life with HIV/AIDS in Sub Saharan Africa. http://www.unaids.org retrieved on 02/02/11.

[4]. Kakar, D.N. \&Kakar, S.N., Combating AIDS in the 21st century issues and challenges, Sterling Publishers Private Limited: India, 2001

[5]. Ghosh, T.K., AIDS A serious challenge to public health, Journal of Indian Medical Association, Jan; 84, 1998, 29-30

[6]. Kallings, L.O., The first postmodern pandemic: 25 years of HIV/AIDS, Journal of Intern Med, 263 (3), 2007, 218-43.

[7]. http://news.oneindia.in/2010/02/26/budget-2010-education-gets-16pc-allocation-hike.html retrieved on 2010/05/02

[8]. Times of India, Sex Education in School, 14 February 1999.

[9]. The World Health Organization, Skills for Health. Information Series on School Health, Document 9, 2009, Geneva, http://www.who.int/hpr, retrieved on 28 October 2011

[10]. National AIDS Control Organization. (2001). Combating HIV/AIDS in India, 2000-2001. Ministry of Health and Family Welfare, New Delhi.

[11]. Global Campaign for Education. http://www.avert.org/aids-schools.htm Retrieved on 5 November 2008.

[12]. Black, J.L., \&Jones, L.H., HIV Infection: Educational Programmes and Policies for school personnel. Journal of School Health, 58(8) 1988, 317-322.

[13]. Tavoosi . L., Zaferani. A., Enzevaei. A., Tajik. P ., and Madinezhad. Z., Journal of Public Health, 17 (4), $2004,4-17$.

[14]. Aggarwal, A.K.,Kumar R., Awareness among school children in Haryana, Indian Journal of Public Health ,40, 1996, 38-45.

[15]. Bhalla S, Chandwani H, Singh D, Somasundaram C, Rasania SK, Singh S. Knowledge about HIV/AIDS among senior secondary school students in Jamnagar, Gujarat. Health Popular Perspective Issues, 28, 2005, 178-88. 